\title{
Correction to: Clinical Quantification of Myocardial Blood Flow Using PET: Joint Position Paper of the SNMMI Cardiovascular Council and the ASNC
}

\author{
Venkatesh L. Murthy, ${ }^{\text {a }}$ Timothy M. Bateman, ${ }^{\mathrm{b}}$ Rob S. Beanlands, ${ }^{\mathrm{c}}$ \\ Daniel S. Berman, ${ }^{d}$ Salvador Borges-Neto, ${ }^{e}$ Panithaya Chareonthaitawee, ${ }^{f}$ \\ Manuel D. Cerqueira, ${ }^{\mathrm{g}}$ Robert A. deKemp, ${ }^{\mathrm{C}}$ E. Gordon DePuey, ${ }^{\mathrm{h}}$ Vasken Dilsizian, ${ }^{\mathrm{i}}$ \\ Sharmila Dorbala, ${ }^{j}$ Edward P. Ficaro, ${ }^{\mathrm{k}}$ Ernest V. Garcia, ${ }^{\mathrm{l}}$ Henry Gewirtz, ${ }^{\mathrm{m}}$ \\ Gary V. Heller, ${ }^{\mathrm{n}}$ Howard C. Lewin, ${ }^{\circ}$ Saurabh Malhotra, ${ }^{\mathrm{p}}$ April Mann, ${ }^{\mathrm{q}}$ \\ Terrence D. Ruddy, ${ }^{\mathrm{c}}$ Thomas H. Schindler, ${ }^{\mathrm{r}}$ Ronald G. Schwartz, ${ }^{\mathrm{s}}$ Piotr J. Slomka, ${ }^{\mathrm{d}}$ \\ Prem Soman, ${ }^{t}$ and Marcelo F. Di Carli ${ }^{\mathrm{j}}$ \\ a Frankel Cardiovascular Center, Division of Cardiovascular Medicine, Department of Internal \\ Medicine, University of Michigan, Ann Arbor, MI \\ b Mid America Heart Institute, Kansas City, MO \\ c National Cardiac PET Centre, Division of Cardiology, University of Ottawa Heart Institute, \\ Ottawa, ON, Canada \\ d Departments of Imaging and Medicine, Cedars-Sinai Medical Center, Los Angeles, CA \\ e Division of Nuclear Medicine, Department of Radiology, and Division of Cardiology, Department \\ of Medicine, Duke University School of Medicine, Duke University Health System, Durham, NC \\ f Department of Cardiovascular Medicine, Mayo Clinic, Rochester, MN \\ g Department of Nuclear Medicine, Cleveland Clinic, Cleveland, OH \\ h Division of Nuclear Medicine, Department of Radiology, Mt. Sinai St. Luke's and Mt. Sinai West \\ Hospitals, Icahn School of Medicine at Mt. Sinai, New York, NY \\ i Department of Diagnostic Radiology and Nuclear Medicine, University of Maryland School of \\ Medicine, Baltimore, MD \\ j Cardiovascular Imaging Program, Brigham and Women's Hospital, Boston, MA \\ k Division of Nuclear Medicine, University of Michigan, Ann Arbor, MI \\ I Department of Radiology and Imaging Sciences, Emory University, Atlanta, GA \\ m Massachusetts General Hospital and Harvard Medical School, Boston, MA \\ n Gagnon Cardiovascular Institute, Morristown Medical Center, Morristown, NJ \\ - Cardiac Imaging Associates, Los Angeles, CA \\ $\mathrm{p}$ Division of Cardiovascular Medicine, Jacobs School of Medicine and Biomedical Sciences, \\ University at Buffalo, Buffalo, NY \\ q Hartford Hospital, Hartford, CT \\ $r$ Division of Nuclear Medicine, Department of Radiology, Johns Hopkins School of Medicine, \\ Baltimore, MD \\ s Cardiology Division, Department of Medicine, and Nuclear Medicine Division, Department of \\ Imaging Sciences, University of Rochester Medical Center, Rochester, NY \\ t Division of Cardiology, Heart and Vascular Institute, University of Pittsburgh Medical Center, \\ Pittsburgh, PA
}

doi: $10.1007 / \mathrm{s} 12350-018-1259-y$

The original article can be found online at https://doi.org/10.1007/ s12350-017-1110-x.

Reprint requests: Venkatesh L. Murthy, University of Michigan, 1338 Cardiovascular Center, SPC 5873, Ann Arbor, MI 48109; vlmurthy@med.umich.edu
J Nucl Cardiol 2018;25:2189-90. 1071-3581/\$34.00

Copyright (C) 2018 American Society of Nuclear Cardiology. 


\section{CORRECTION TO: J NUCL CARDIOL 2018;25:269-97}

HTTPS://DOI.ORG/10.1007/S12350-017-1110-X

The above position statement originally published containing errors in the author metadata; specifically, the Expert Content Reviewers-Andrew Einstein, Raymond Russell and James R. Corbett-were tagged as full authors of the paper. The article metadata has now been corrected to remove Drs. Einstein, Russell and Corbett from the author line, and the PubMed record has been updated accordingly.

This correction pertains only to the author metadata; no further changes to the position statement were made. 